\title{
(t)
}

\section{ABUSOS SEXUAIS NO EMPREGO DOMÉSTICO NO RIO DE JANEIRO: A IMBRICAÇÃO DAS RELAÇÕES DE CLASSE, GÊNERO E "RAÇA"}

\author{
SEXUAL ABUSE IN DOMESTIC WORK IN RIO DE JANEIRO: THE \\ OVERLAP OF CLASS, GENDER AND “RACE” RELATIONS
}

\section{Valeria Ribeiro Corossacz ${ }^{2}$}

\section{INTRODUÇÃO}

Neste artigo, abordo a temática dos assédios sexuais contra as trabalhadoras domésticas, utilizando os dados de duas pesquisas conduzidas no Rio de Janeiro. Na primeira, realizada entre 2009 e 2012, entrevistei 21 homens da cidade do Rio de Janeiro, com idade entre 43 e 60 anos, os quais se autodefinem brancos e de classe média alta. Nessas entrevistas, enfrentei diferentes aspectos das experiências biográficas relativas à branquitude e à masculinidade (RIBEIRO COROSSACZ, 2010, 2014a, 2014b, 2015). Um dos aspectos mais salientes diz respeito aos relatos sobre o acesso sexual ao corpo da trabalhadora doméstica pelo jovem homem branco de classe média alta. Trata-se, portanto, de histórias que remontam à adolescência dos homens entrevistados.

Decidi prosseguir o trabalho sobre os abusos sexuais contra as trabalhadoras domésticas desenvolvendo outra pesquisa, em 2013, na qual entrevistei empregadas e sindicalistas do Sindicato das Empregadas Domésticas do Rio de Janeiro acerca

1 Título original: L'abus sexuel dans l'emploi domestique au Rio de Janeiro: I' imbrication des rapports de classe, sexe et la race. Tradução de Emilie Raymond. 2 Professora de antropologia do Dipartimento di Studi Linguistici e culturali Università degli Studi di Modena e Reggio Emilia- Itália. E-mail: valeria.ribeirocorossacz@unimore.it. 


\section{temporalis}

da temática dos abusos sexuais contra as trabalhadoras domésticas ${ }^{3}$. Enquanto na primeira pesquisa me focalizei na questão de entender como os abusos sexuais contra as empregadas domésticas são um elemento constitutivo de uma branquitude masculina heterossexual de classe alta, na pesquisa com as trabaIhadoras domésticas busco compreender a vivência dessa violência, assim como as estratégias individuais e políticas que visam a contrastá-la.

Nesses dois trabalhos, reflito a respeito da ligação entre trabalho doméstico remunerado e serviço sexual e de como essas experiências de abusos sexuais acontecem na interseção de diferentes relações de dominação: entre sexos, entre classes sociais e entre "raças" (CRENSHAW, 1989, 1991). No Brasil, os abusos sexuais contra as trabalhadoras domésticas perpetrados pelos próprios empregadores se caracterizam, com efeito, pelo fato de condensar a imbricação de relações de poder entre diferentes grupos e a conflitualidade que deriva disso. Não se trata apenas de uma violência sexista, mas também de uma violência racista e de classe, considerando que, como podemos verificar, nela se combinam as desigualdades de "raça", de classe e de sexo, típicas da sociedade brasileira, que produz formas determinadas de opressão e de privilégio social. Tentarei, então, na análise dos abusos sexuais contra as empregadas domésticas, desenvolver uma apreensão cruzada das relações de poder baseadas nas classificações sociais de sexo, de "raça" e de classe (KERGOAT, 2009).

A partir dos testemunhos de alguns homens entrevistados em relação aos abusos sexuais, procuro compreender as características dessa violência, apoiando-me precisamente na capacidade deles de falar da violência dessas relações. Essa análise permite entender como essa violência é naturalizada e como está apagada a dimensão do racismo presente nela. A característica do material apresentado é de tratar a temática dos abusos sexuais contra as trabalhadoras domésticas dando também espaço às

3 A pesquisa, ainda em andamento, é realizada com o apoio da Università degli Studi di Modena e Reggio Emilia (Itália), Dipartimento di Studi Linguistici e Culturali, projeto PRIN 2010-2011: Stato, pluralità e cambiamento in Africa 201048XHTL_004. 
palavras do grupo que se encontra em uma posição dominante no seio das relações descritas.

\section{ABUSOS SEXUAIS E TRABALHO DOMÉSTICO}

A violência sexual, entendida como abusos verbais, físicos, até chegar ao estupro, contra as trabalhadoras domésticas não é um fenômeno específico Brasil (WADE, 2013). Diz respeito a uma realidade presente em sociedades muito diferentes umas das outras. No caso do Brasil, trata-se de uma questão muita conhecida, mas pouco analisada na literatura científica: não encontrei pesquisas voltadas especificamente aos abusos sexuais contra as empregadas domésticas, mesmo que nos estudos existentes possamos encontrar referências que levem a entender que se trata de um fenômeno habitual bem conhecido (BRITES, 2007; SANTOS, 2009; GOLDESTEIN, 2003; BERNARDINO-COSTA; FIGUEIREDO; CRUZ, 2011). Alguns motivos que podem explicar o pouco de documentação existente sobre esse tipo de abuso contra as trabalhadoras domésticas poderiam ser, entre os membros da burguesia branca, as resistências a reconhecer a violência desses episódios e, entre as empregadas domésticas, as dificuldades de falar desse assunto, sobretudo no passado. Conforme veremos, houve durante esses últimos anos algumas mudanças importantes em relação à autopercepção da condição de empregada doméstica.

O material das entrevistas permite examinar também uma relação que fica frequentemente escondida quando se fala do trabalho doméstico e de empregadas domésticas: a relação entre o homem empregador e as trabalhadoras domésticas. A análise dessa relação é uma passagem que se deve levar em conta para compreender por que e como se produzem os abusos sexuais contra as empregadas domésticas.

A literatura brasileira sobre o trabalho doméstico é rica, mas enquanto existem estudos a respeito da relação entre empregadora e empregada doméstica, não me foi possível encontrar pesquisas referentes ao modo como se caracteriza a relação entre empregador e empregada doméstica. Em minha opinião, o motivo desse vazio reside no fato de que há uma tendência a não olhar para quem é feito, no seu conjunto, o trabalho doméstico 


\section{temporalis}

e de reprodução social cumprido pelas mulheres, a saber: para homens. Mesmo quando esse trabalho é relacionado às crianças, o fato de que os homens não sejam considerados como responsáveis desse trabalho chega a fazer esquecer que esse trabalho é também realizado para eles, como pais.

Muitas vezes nos interrogamos sobre os mecanismos de opressão entre as mulheres na gestão do trabalho doméstico, dando o exemplo clássico da mulher branca de classe média urbana que trabalha fora de casa enquanto outra mulher, pobre, imigrante de outro país ou de regiões pobres do seu próprio país, não branca, deixa sua família e seus filhos para cumprir no lugar dela o trabalho doméstico e de cuidado. Encontramos também essa reflexão nas pesquisas brasileiras. Nessa representação da realidade, o homem, como esposo, pai ou parente da mulher de classe média, desaparece, pois está absolvido pela sociedade do peso do trabalho doméstico e de cuidado. Como escreve da Mata Azeredo (1989, p. 200), as empregadas domésticas são "mulheres que assumem o trabalho doméstico para outras mulheres". Dessa forma, a divisão sexual do trabalho doméstico e de cuidado somente é percebida como um problema que tem a ver com as mulheres, bem como uma forma de discriminação entre as mulheres. Essa situação representa um problema que deve ser discutido dentro da perspectiva feminista, devendo também ser considerada a posição dos homens, como classe social, no seio dessa situação, para entender por que o trabalho doméstico está repartido entre categorias de mulheres, continuando a ser uma tarefa reservada exclusivamente às mulheres de classe e de origem diferentes.

Parece-me, de fato, que existe um elemento que une as mulheres, mesmo considerando as diferenças de classe social, de origem geográfica, de "raça", a saber: o fato de que o trabaIho doméstico e de cuidado, de graça e/ou retribuído, é realizado pelas mulheres para os homens e de que esse trabalho doméstico e de cuidado é fortemente associado ao serviço sexual, fora do casamento ou não. Talvez fosse mais fácil observar esse elemento que une as mulheres se, quando analisássemos o trabalho doméstico, deslocássemos a atenção para a posição dos homens. 


\section{CONTEXTO E CONDIÇÕES DO TRABALHO DOMÉSTICO}

De acordo com o pesquisador Owensby (1999), a figura da empregada doméstica representa um elemento central para a afirmação da identidade da classe média brasileira no período de 1920 a 1950, pois marca a diferença entre uma classe que não se deve ocupar do trabalho manual e uma outra destinada, ao contrário, a cumpri-lo. Segundo diferentes pesquisadoras, essas observações seriam igualmente válidas para épocas mais recentes. Kofes (2001, p. 217) observa que a presença das empregadas domésticas nas casas da classe média alta não está ligada à necessidade das mulheres de classe média de trabalhar fora da sua casa, porque é anterior à inserção das mulheres no mercado do trabalho. Silva (2010, p. 22) observa como "a facilidade de acesso ao trabalho de outros resulta das desigualdades econômicas" típicas do Brasil e o quanto "o emprego de uma ajuda doméstica paga aumenta com o salário e a brancura da pele" (SILVA, 2010, p. 23). Com certeza, apesar de raramente explicitado, a classe média alta está identificada com indivíduos brancos, criando uma associação entre a classe média alta e a cor branca, que começou a mudar apenas no curso dessas últimas décadas (FIGUEIREDO, 2002; SILVA; REIS, 2011).

Kofes (1993, p. 190) comenta ainda que "o cotidiano familiar das classes superiores funciona incorporando mulheres de classes inferiores e o universo doméstico é recriado nos termos de uma relação mando/obediência". A relação de comando está presente igualmente nas experiências dos homens entrevistados, referindo-se a um período que vai do final de 1960 até o início de 1980. Alguns dentre eles contaram a maneira como a empregada doméstica e, em geral, os vários trabalhadores empregados na casa onde moravam eram considerados pessoas inferiores em relação à família e ao meio social deles. Alguns contaram como Ihes foi ensinado a provar um sentimento de superioridade social em frente a eles e a ter uma função de comando nas relações com eles. Mesmo socialmente inferiores, os empregados domésticos eram considerados como fazendo parte da família, entendida como um espaço de relações íntimas e afetivas. Frequentemente, os entrevistados se lembram da empregada doméstica como uma pessoa dedicada, não apenas uma trabalhadora, mas uma pessoa 


\section{temporalis}

que cuidava da família (SILVA, 2010). Se essa transposição de trabalho para dedicação é recorrente quando se refere ao trabalho de cuidado que as mulheres cumprem, anulando assim o caráter de trabalho dessas atividades, aqui essa mesma transposição soa ainda mais cruel, por se tratar de uma atividade remunerada. Em geral, como cita Ávila (2008, p. 69), no Brasil, ter lembranças da "babá", da empregada doméstica "configura a estética burguesa"; essas memórias "são parte de seu status de classe".

Assim, a presença das empregadas domésticas em casa, de um lado, comportava o fato de serem consideradas como fazendo parte da família e, de outro lado, indicava a condição social de classe média da família, que é, ao mesmo tempo, de classe e de cor. Há aqui uma combinação entre intimidade e separação claramente representada pela utilização dos espaços domésticos e particularmente pelo uso dos banheiros e sanitários separados (KOFES, 2001).

Levemos agora em consideração as condições das trabalhadoras domésticas durante o período ao qual se referem as experiências contadas pelos homens, a saber: as décadas de 1960/1980. O trabalho doméstico era uma das principais atividades para as mulheres sem instrução e qualificação. A maioria das empregadas domésticas vinha do campo para a cidade: para elas, o trabaIho doméstico era a primeira via de socialização na cidade, mas também uma forma de ter um alojamento, comida e uma família (MELO, 1989, p. 247). Muitas empregadas domésticas moravam na casa onde trabalhavam. A retribuição delas consistia em um salário mensal, do qual uma parte era frequentemente contabilizada em comida e alojamento, mas não era raro que a comida e o alojamento fossem considerados como a única forma de retribuição. As condições de vida e de trabalho dessas mulheres eram caracterizadas por uma jornada de trabalho sem horário (o que é também uma consequência do fato de morar no mesmo lugar onde se trabalha), pelo isolamento, pela inserção forçada no meio da família e de suas dinâmicas, como também pelo fato de serem obrigadas a ter como único espaço pessoal um quarto de alguns metros, geralmente sem janela, com uma abertura para ventilação, situado ao lado da cozinha (OLIVEIRA; CONÇEIÇÃO, 1989). 


\section{A CONTINUIDADE ENTRE A FIGURA DA ESCRAVA DE ORIGEM AFRICANA E A DA TRABALHADORA DOMÉSTICA}

A literatura sobre as empregadas domésticas sempre se deteve na continuidade entre a figura da escrava de origem africana e aquela da trabalhadora doméstica, percebida pelas pesquisadoras, pelas empregadoras entrevistadas e também pelas empregadas domésticas (MELO, 1989; KOFES, 2001). Vemos aparecer também nas palavras dos homens entrevistados e das mulheres sindicalistas referências à continuidade entre escrava e empregada doméstica.

Essa continuidade se constrói também sobre a cor implícita nas definições de empregada doméstica e de família de classe média. Segundo um recente estudo,

de fato, o trabalho doméstico é - e sempre foi uma ocupação desempenhada majoritariamente por mulheres e negras. O perfil dessa ocupação remonta não só às raízes escravistas da sociedade brasileira, mas também às tradicionais concepções de gênero, que representam o trabalho doméstico como uma habilidade natural das mulheres (IPEA 2011, p. 4) $)^{4}$

Uma das formas sob a qual se manifesta a negação do racismo é notoriamente a não produção de dados estatísticos sobre suas manifestações. É assim que temos que interpretar a ausência de dados estatísticos sobre a cor das empregadas domésticas relativos aos anos 1960/1980. Atualmente, cerca de $61 \%$ das empregadas domésticas são negras (ÁVILA, 2010, p. 129). Num estudo sobre as trabalhadoras domésticas negras do Rio de Janeiro na década 1980, aparece que elas mesmas estabeleciam uma ligação entre o fato de serem negras e de exercerem esse tipo de profissão (SANTOS-STUBBE, 1998, p. 58). As referências à continuidade entre escrava e empregada doméstica concernem também à "disponibilidade sexual" requerida delas, estabelecendo uma ligação entre a "disponibilidade" da escrava no espaço da casa-grande da época colonial e a "disponibilidade" da trabalhadora doméstica nos apartamentos urbanos. Como

4 Ver também Melo (1998). 


\section{temporalis}

disse um entrevistado, as características da escrava que persistem no presente são aquelas de "uma figura disponível. Uma mulher dentro da casa submissa e que estaria disponível sexualmente". Existiria assim uma disponibilidade que não é apenas ilimitada no tempo (ÁVILA, 2010), mas também nas funções. O serviço sexual seria quase constitutivo da submissão própria do trabalho doméstico. A continuidade culturalmente estabelecida entre escrava e empregada doméstica participa da definição da ligação entre serviço doméstico e serviço sexual, mas isso não é suficiente para entender as transformações e os significados que essa ligação tem no presente.

Apesar de essa continuidade entre escrava e empregada doméstica ser reconhecida, os homens entrevistados fazem raramente alusão à cor de pele da empregada doméstica, sendo a sua condição de classe tida como mais importante. Mesmo que haja um consenso geral entre os entrevistados sobre o fato de que no Brasil as empregadas domésticas são na maioria negras, a cor dessas trabalhadoras, individualmente falando, não é considerada como um elemento importante para entender as próprias experiências com elas. Trata-se, sobretudo, de uma informação que não é dada espontaneamente durante a entrevista. Há um deslizamento contínuo entre classe e cor no que diz respeito à figura da empregada: a condição dela é historicamente aquela de uma mulher negra ou não branca; sua cor seria quase produzida pela condição social e profissional.

\section{OS ABUSOS SEXUAIS: OS RELATOS DOS HOMENS}

Os homens entrevistados possuem entre 43 e 60 anos, moram em bairros ricos ou de classe média alta do Rio de Janeiro, todos têm diplomas de estudos superiores, alguns com doutorado, títulos que permitem a eles ter um perfil profissional qualificado, certo status social e bem-estar econômico. Dos 21 homens entrevistados, três têm relações afetivas e sexuais com outros homens, um não se expressou claramente, deixando a entender que ele tinha tido relações tanto com homens quanto com mulheres, e os outros dezessete se relacionam com mulheres.

Os entrevistados em idade avançada estabeleceram relações afetivas duráveis somente com pessoas brancas. Aqueles 
que têm filhos os tiveram com mulheres brancas e definem seus próprios filhos como brancos. A presença de mulheres negras na vida sentimental dos entrevistados é muito limitada e está ligada à época da sua juventude e dentro de relações ocasionais. A característica dessas pessoas é de ter vivido durante a infância e adolescência em um ambiente onde os negros estavam presentes, mas quase sempre no mundo dos serviços.

Todos os entrevistados, tanto os que moram sozinhos quanto os que vivem com uma companheira, empregavam no momento da entrevista uma ou várias mulheres que cuidavam dos trabalhos de casa. À exceção de um entrevistado, todos cresceram dentro de famílias nas quais havia uma ou várias empregadas domésticas. Como observado por várias pesquisadoras, o fato de que o trabalho de casa seja uma atividade exercida por pessoas exteriores à família é considerado normal e desejável na sociedade brasileira (GOLDESTEIN, 2003; BRITES, 2007; PINHO; SILVA, 2010) ${ }^{5}$. Na opinião de Kofes (2001, p. 171), as próprias empregadas domésticas não conseguem conceber uma sociedade sem empregadas.

No ambiente a que pertencem os entrevistados, o acesso sexual ao corpo das empregadas domésticas era frequentemente considerado uma "iniciação sexual” dos jovens, e é assim que nós falamos disso durante a entrevista. Como iremos ver, trata-se de formas de abusos sexuais, ou até mesmo de estupro em alguns casos, descritos pelos entrevistados em toda a sua violência, mesmo que eles os considerassem como "normais".

Dos 21 entrevistados, oito contaram ter tido "iniciação sexual" com uma empregada. Entre eles, há dois dos três entrevistados que têm relações afetivas com homens, ou seja, que se afastaram somente na idade adulta do modelo de afetividade e de sexualidade heterossexuais. Por "iniciação sexual”, não deve ser entendida necessariamente a primeira relação sexual com penetração vaginal, mas as primeiras aproximações a uma sexualidade heterossexual e heteronormativa.

5 E não só na sociedade brasileira. 


\section{temporalis}

Os homens que não tiveram relação sexual com as empregadas domésticas reconheciam esse tipo de relação como um hábito social muito comum, do qual eles tinham conhecimento e do qual se falava entre coetâneos. Um entrevistado, o único que cresceu em uma família sem empregada doméstica, contou: "Nós não tínhamos [a iniciação sexual com a empregada, n. d. t.] não porque éramos bonzinhos. É porque não tínhamos empregada" (Mino, 59 anos).

Uma expressão evocada por alguns entrevistados é TED: terror das empregadas domésticas. O terror seria personificado pelos jovens rapazes brancos de classe média que assediam as trabalhadoras domésticas. A expressão TED, usada pelos jovens coetâneos com um tom de brincadeira, deixa a entender que havia uma consciência do nível de violência ("terror”) que produzia o comportamento desses jovens contra as empregadas, mas essa violência é banalizada através da ironia com a qual esse acrônimo era usado.

Vários entrevistados estabeleceram uma ligação entre o fato de que era comum para um menino da mesma classe social ter as suas primeiras atividades sexuais com uma empregada (ou com uma prostituta) e a impossibilidade de ter relação sexual com meninas do mesmo nível social. As garotas de sua idade e do seu mesmo nível social não estavam, aparentemente, disponíveis a ter relações sexuais, sobretudo aquelas que incluíam a penetração, pois isso poderia prejudicar a reputação delas. A sexualidade masculina dos adolescentes é de fato representada nas entrevistas como um aspecto fisiológico, hormonal, que se impõe como uma necessidade para a qual se deve encontrar uma resposta apropriada. A empregada doméstica tem a função de responder a essa necessidade dos jovens garotos brancos de classe média.

Alguns deles relataram que a "iniciação sexual" com uma empregada era implicitamente valorizada ou tolerada pelo pai ou por parentes de sexo masculino. Essa "relação sexual" era considerada um momento de passagem, que representava para o homem a entrada na idade adulta, mas que era também o testemunho de uma masculinidade espontânea, autêntica, permitindo provar que eles não eram homossexuais. 
Nas entrevistas, são raros os relatos de como ocorriam o abuso ou as bolinações com a empregada. Porém, os entrevistados se detiveram no contexto social em que essas violências aconteciam. Muitos descreveram uma situação de relações de poder, nas quais a empregada era representada como totalmente submissa aos desejos de seus patrões. Há nas entrevistas a ideia segundo a qual a empregada estaria totalmente à disposição, inclusive através do serviço sexual.

Enfim, é uma classe inferior da pessoa, tá aí para
me servir. Não tá me servindo o dia todo? Por que
não pode me servir na cama também? Por que não
pode sentar aqui no meu colo? Por que não satisfa-
zer o meu desejo sexual? Porque a relação de pa-
trão e empregada doméstica no Brasil ainda é muito
complicada. Naquela época era mais ainda (Julio, 51
anos).
Eu me lembro que os garotos da minha idade, quan-
do eu era adolescente, muitos que não transavam
ainda, transavam com as empregadas, isso um ami-
go do meu irmão. Eu lembro essa história dele me
contar que ele ia lá atrás e depois... como se fosse...
Você vê, [a empregada, n. d. t.] é tratada como ani-
mal (Carlos, 52 anos).

Alguns afirmaram que esse tipo de situação era considerado "normal". Segundo um entrevistado, "era uma coisa culturalmente aceita [...]. Havia a ideia explícita e subentendida que transar com as empregadas seria mais fácil. Então, quando se tinham catorze ou treze anos, saíam com empregada" (Mario, 49 anos).

Nessas partes de entrevista, há uma descrição precisa da relação de poder que permitiu exercer uma violência sobre as empregadas. Esses homens sabem que se trata de uma forma de violência e, ao mesmo de tempo, não há nenhuma forma de censura ou de embaraço: o que se mostra é uma aceitação da assimetria dessas relações (de sexo, classe e "raça") descritas como um fato inevitável, intrínseco ao mundo, ao mundo deles. Essa atitude comporta a percepção de uma situação "normal”, por mais que no momento da entrevista ela possa ser considerada por alguns entrevistados como detestável. Essa sensação corrente de "normalidade" deveria igualmente estar ligada com o hábito, 


\section{temporalis}

tão enraizado, de considerar normal que o trabalho doméstico seja efetuado por uma mulher exterior à família, pobre, negra ou não branca.

A característica dos testemunhos desses homens é de oferecer a possibilidade de entender uma relação de dominação examinando a descrição que é feita por quem está na posição dominante. Como observa Nicole-Claude Mathieu (1991, p. 147), "a consciência dominante pode também ser mistificada [...], mas o dominante conhece os meios da exploração e da dominação". O sujeito dominante pode ser, portanto, preciso na descrição dos mecanismos da dominação, às vezes mais do que poderia ser o sujeito dominado. $\mathrm{Na}$ análise dessas partes das entrevistas, é possível compreender como essa violência é banalizada, baseando-nos precisamente na capacidade desses homens de falar da violência dessas relações. Porém, há uma diferença entre o conhecimento da dominação e a experiência da opressão. Segundo Mathieu (1991, p. 148), "se um dominante conhece a dominação, ele não conhece a experiência da opressão, ou seja, o outro lado". Por essa razão, é interessante aproximar as duas experiências, ouvindo agora os relatos das mulheres sindicalistas e das empregadas domésticas.

\section{OS ABUSOS SEXUAIS: OS RELATOS DAS MULHERES}

Em 2013, entrevistei 4 mulheres sindicalistas do Sindicato das Empregadas Domésticas do Rio de Janeiro que trabalhavam, ou trabalharam, como empregadas domésticas, a advogada que oferecia de graça consultas jurídicas ao sindicato, uma militante de uma organização das mulheres negras, uma faxineira aposentada e quatro ainda em atividade, essas últimas não participando das iniciativas do sindicato. A advogada era branca, as outras participantes eram negras ou originárias da região Nordeste. $\mathrm{Na}$ base dessas entrevistas, desenvolverei algumas primeiras observações, cujo objetivo é contribuir para compreensão da situação atual dos abusos sexuais contra as trabalhadoras domésticas.

A primeira observação a fazer é que, segundo as sindicalistas, não é muito corrente que as empregadas domésticas se dirijam a elas para denunciar as violências sexuais sofridas. É um argumento sobre o qual elas têm dificuldades de falar, mesmo 
com as sindicalistas, que, como elas próprias observaram, são mulheres. Na opinião de algumas delas, seria um sentimento de vergonha que as impediria de contar os abusos sofridos. Em alguns casos, as sindicalistas têm a impressão de que houve alguns episódios de abusos, mas elas percebem que as empregadas têm uma resistência grande a nomear essas violências e, ao mesmo tempo, demonstram um sentimento profundo de raiva contra o patrão. A dificuldade de nomear esse tipo de violência deve estar relacionada também com o fato de que, quando as empregadas contam esses episódios, elas quase nunca são acreditadas pela esposa e pela família do patrão e, além disso, elas são demitidas. Uma das raras fontes disponíveis sobre as violências contra as empregadas domésticas nos anos 1960 e 1970 conta como no passado era impossível de se denunciar as violências sofridas, inclusive as violências sexuais, pois isso significava não somente perder o emprego, mas também o alojamento onde se morava e trabalhava, ficando completamente sozinha, uma vez que, vindo do campo, as trabalhadoras domésticas não tinham nenhuma relação na cidade (SANTOS, 2009, p. 101).

Segundo os relatos das sindicalistas e das empregadas domésticas, nos casos de abusos sexuais, a patroa quase nunca acredita na trabalhadora, mas ela defende o marido ou lhe justifica, e tende a demitir a empregada. Frequentemente, acontece a reviravolta clássica na qual não é o homem que teria assediado a mulher, mas a mulher que teria provocado o homem ou mentido sobre os assédios sofridos. Tendo em vista que, em vários casos, essas mulheres não podem perder seu emprego, essa situação se transforma numa restrição de sua própria liberdade de escolha e de ação. Uma sindicalista lembra como o perfil dessas mulheres que não conseguem falar é muitas vezes aquele de mulheres geralmente "sozinhas, que não têm marido. São chefes de família. Pra não perder o emprego, elas ficam quietas e não... Não falam nada". Uma primeira dificuldade, portanto, concerne precisamente à possibilidade de nomear os abusos sofridos e de serem acreditadas, o que torna difícil a avaliação da extensão efetiva desse fenômeno. O silêncio sobre a questão dos abusos sexuais deve então ser interpretado como uma impossibilidade das trabalhadoras domésticas de nomear e, portanto, de denunciar 


\section{temporalis}

esse tipo de violência, e não como um indicador de sua ausência, como, aliás, ocorre em qualquer caso de abusos sexuais contra as mulheres.

A dificuldade em denunciar esses abusos é, ao mesmo tempo, estreitamente ligada a essa cultura da classe média branca, que admite ou tolera os assédios sexuais contra as empregadas domésticas, representados como uma forma de iniciação sexual masculina ou como uma expressão legítima para dar livre curso a uma sexualidade masculina definida como incontrolável.

As sindicalistas e trabalhadoras entrevistadas consideram que, em relação ao passado, é possível que hoje os abusos sexuais contra as empregadas domésticas sejam menos comuns. Durante os encontros nacionais do sindicato, as sindicalistas notaram, todavia, que em outros estados esse problema é mais presente na vida das empregadas domésticas. Efetivamente, o Rio de Janeiro é uma cidade grande onde as experiências de reivindicações políticas estão mais enraizadas e os salários das empregadas domésticas estão entre os mais altos do país. No sindicato, há uma forte consciência de que o fenômeno dos assédios sexuais existe, de que ele é frequente e de que muitas vezes é silenciado até pelas empregadas domésticas. É precisamente por essa razão que essa temática é sempre abordada nos seminários de formação organizados pelo sindicato com o objetivo de criar as condições para falar dos assédios sexuais e estimular as empregadas a denunciar ou de qualquer forma a reagir. Existe uma ideia corrente, compartilhada tanto pelas sindicalistas quanto pelas empregadas domésticas, segundo a qual hoje em dia as jovens trabalhadoras estariam mais propensas a reagir aos assédios, porque elas estão mais conscientes dos seus próprios direitos.

Das entrevistas, destaca-se que o perfil do homem que hoje abusa das empregadas domésticas corresponde àquele de um homem branco de idade média ou avançada, de classe média alta. Não recolhi nenhum testemunho sobre jovens homens brancos de classe média alta, filhos do casal para quem trabalha a empregada, protagonistas de abusos sexuais contra ela. O modelo de "iniciação sexual" com a empregada doméstica, tão corrente e valorizado nos ambientes dos homens de 40 a 60 anos, hoje 
em dia não é mais, parece, tão comum entre os adolescentes ${ }^{6}$. Essa situação é geralmente relacionada com as mudanças ocorridas nos comportamentos sexuais: hoje as meninas são descritas como mais "livres", quer dizer, que as relações sexuais entre adolescentes de mesmo nível social são socialmente permitidas, inclusive antes do casamento. Segundo a advogada,

as namoradas hoje já começam a ter relação sexual. Antigamente não. Antigamente o sexo era uma coisa muito proibida. Então o que ele tinha mais próximo ali dele, ou era prostituta ou era empregada doméstica, que tava ali dentro de casa e que ele sabia que não ia abrir a boca, né?

Nessa descrição, encontramos a ideia, já formulada pelos homens entrevistados, conforme a qual a sexualidade dos jovens homens brancos de classe média alta seria irrepreensível, e segundo a qual, também em face da recusa das moças da mesma classe social de ter relações sexuais, eles "se desafogavam" com mulheres de extração social mais baixa. O que me parece importante no relato da advogada é a capacidade de descrever a ideia da disponibilidade sexual da empregada doméstica que, como um objeto, se encontra "ali dentro de casa" e que se pode pegar. 0 espaço da casa dá um conteúdo específico à ideia corrente de que todas as mulheres estão disponíveis para os homens: trabalhar dentro de uma casa significa estar incluída dentro de um espaço ressentido pelo homem/patrão como familiar e íntimo, do qual ele é o dono legítimo. A expressão brasileira "trabalhar em casa de família”, para indicar o trabalho doméstico remunerado, carrega bem essa ideia de que não se trabalha apenas dentro de uma casa, mais também dentro de uma família, que, porém, não é uma família no sentido geral, mas uma família de classe média branca (MCCALLUM, 2007). Essas experiências de trabalho doméstico e de abusos sexuais, então, têm uma conotação clara em termos de relações de classe, "raça" e sexo, mesmo sendo necessário decifrá-las, porque essas experiências são representadas como

6 Seria, todavia, importante conduzir uma pesquisa com jovens brancos de classe média alta para analisar as representações e as opiniões deles em relação a esse modelo. Parece, de acordo com algumas breves conversações, que as brincadeiras com conotação sexual sobre a empregada doméstica ainda subsistem. 


\section{temporalis}

neutras, conforme aparece na expressão "trabalhar em casa de família". Encontramos face a uma imbricação das relações de poder que devem ser compreendidas como tais, a saber na sua complexidade e na sua definição recíproca.

A razão pela qual hoje em dia são homens de idade média os responsáveis pelos assédios sexuais reside no fato de que eles ainda estariam ligados à mentalidade que apresenta as empregadas domésticas como totalmente submissas por serem pobres, de classe popular e, ainda, vistas como escravas. Como diz a advogada: “É esse homem com idade que vai atrás da empregada. Que ainda tem aquela consciência de que: ah, ela vai ficar quieta. Eu posso... Eu sou doutor, então ela vai ter medo de me denunciar e achar que é mentira. É a minha palavra contra a dela”.

É bom de notar que a expressão “doutor” não indica apenas uma posição de classe e de status, mas também de cor: dizer "doutor" significa ainda dizer "branco". A advogada explica também outro mecanismo dessa experiência de abusos: a negação por parte dos homens da possibilidade de que as empregadas domésticas possam se revoltar e falar, sendo isso uma parte integrante do exercício da dominação.

Um dos objetivos mais importantes do sindicato das empregadas domésticas é precisamente investir em um discurso que quebre a percepção e a autopercepção dessas trabalhadoras como mulheres sem direitos e, assim, destinadas a sofrer qualquer condição de trabalho, inclusive o assédio sexual. Como observa a presidente do sindicato nacional das empregadas domésticas, "o trabalho do sindicato é também de conscientização, de valorização da mulher trabalhadora, de resgate de sua autoestima, de luta contra as marcas do racismo" (OLIVEIRA, 2008, p. 112).

Para combater as violências sexuais no contexto do trabalho doméstico, é importante transformar a mentalidade que concebe as empregadas domésticas como mulheres incapazes de reagir e de obter o respeito dos próprios direitos e a sua própria dignidade como pessoas. A advogada considera que "as pessoas não chegam a cometer o assédio porque veem que é uma pessoa informada". Se apresentar como uma pessoa informada parece poder garantir reconhecimento e respeito social maiores 
e, assim, romper uma relação de submissão que seria o contexto em que acontecem esses tipos de abusos sexuais.

De acordo com um recente estudo realizado em duas cidades brasileiras, as empregadas domésticas que sofrem abusos sexuais saem do seu próprio local de trabalho (BERNARDINOCOSTA; FIGUEIREDO; CRUZ, 2011). Foi igualmente constatado durante a minha pesquisa que algumas empregadas domésticas saem do emprego quando elas sofrem abusos sexuais. Trata-se de uma forma de revolta contra a violência e de exercício da sua própria subjetividade. A possibilidade de apresentar queixa na justiça representa uma passagem ulterior que, entretanto, arrisca ser apenas uma fonte de frustração. Se para as empregadas domésticas não é fácil falar com as sindicalistas desse tipo de experiências, podemos imaginar o quanto é difícil tomar a decisão de denunciar a violência sexual às autoridades. Muito raros são os casos em que as trabalhadoras domésticas decidem apresentar queixa e empreender o percurso judiciário. Essa situação também ocorre porque é praticamente impossível vencer tal causa. A advogada do sindicato conta que ela nunca conseguiu ganhar um processo contra o empregador por violência sexual, pois é impossível provar que a violência aconteceu. Como afirma a advogada, é a palavra da empregada contra a do seu empregador, e aquele que deve julgar tem fortes preconceitos contra a empregada. A advogada explica nesses termos a situação: "os empregadores de domésticas estão em toda parte. Ele é juiz, ele é advogado, ele é desembargador, Ministro, político". Em todas essas figuras, encontramos um homem que tem uma empregada doméstica, um homem de classe média alta, branco. Esses relatos parecem indicar um mecanismo implícito, quase automático, de identificação entre o homem que deve julgar e o homem que é acusado, criando uma cumplicidade baseada no fato de pertencer à mesma classe, à mesma "raça" e a uma mesma cultura que ironiza e legitima os assédios sexuais contra as empregadas domésticas.

Enfim, também nas entrevistas com as sindicalistas, é reconhecida uma ligação entre o fenômeno dos abusos sexuais contra as trabalhadoras domésticas e a escravidão. As sindicalistas observam, sobretudo nos empregadores, a tendência a estabelecer uma continuidade entre escrava e empregada doméstica, 


\section{temporalis}

o que justificaria a apropriação total da pessoa até chegar aos abusos sexuais. Essas sindicalistas creem, porém, que se trata de um comportamento frequente, sobretudo entre os mais velhos, e salientam a importância das mudanças que estão ocorrendo. $\mathrm{O}$ papel do racismo nas experiências do trabalho doméstico é uma questão importante para as sindicalistas, porém não foi possível aprofundar se para elas existe alguma ligação entre racismo e abusos sexuais contra as trabalhadoras domésticas.

\section{COMO ISSO ACONTECE}

Enquanto os homens descrevem o contexto das relações com a empregada doméstica que legitima os abusos sexuais, as empregadas domésticas e as sindicalistas contam como isso ocorre. Aparece nas entrevistas que os abusos acontecem geralmente da seguinte forma: o homem se apresenta nu ou com o seu sexo fora da calça; ele procura encostá-lo na empregada, que procura se esquivar, às vezes trancando-se dentro de um quarto. Também é comum que o homem se esfregue na trabalhadora doméstica ou a apalpe enquanto ela trabalha (lava, cozinha).

Eu trago aqui a história de Antônia, uma mulher de 71 anos, aposentada, que aprendeu a ler e a escrever aos 40 anos, quando ela já era mãe. Na época dos fatos, ela morava numa cidade do Nordeste do país, na qual tinha chegado para trabalhar aos 13 anos, vindo do campo onde até então tinha morado com a família. A sua primeira experiência de abuso aconteceu dentro de uma casa onde o patrão batia com força contra a porta do quarto dela, aterrorizando-a: ela não conseguia reagir e ficava muda. Depois, foi trabalhar em outra casa, tomando conta da cozinha enquanto outra menina cuidava das crianças.

Essa foi dura. O homem saía pelado atrás de mim e eu: meu Deus! Quando eu olho o homem pelado do meu lado. Eu: ai, meu Deus, que que eu vou fazer? Eu: pelo amor de Deus, o senhor saia daqui. Ele fazia assim: cala a boca, Antonia. Eu não vou calar porque o senhor tá aí. Sua esposa dá surra nas outras empregada que esteve aqui porque o senhor é muito abusado. Aí ele saía na carreira de mim, aí tinha uma mesa de oito cadeiras. Eu pegava, empurrava a mesa lá pro canto que era pra dar um tempo, 
imprensar ele... Eu e minha colega, nós abria a porta pra ir pro meio da rua.

A dinâmica descrita aqui é muito frequente. Vemos como as empregadas domésticas tentam se defender, esquivando-se fisicamente do agressor. A insistência com a qual o homem pede à mulher para ficar calada indica o exercício de um poder que jamais pode ser total: as mulheres podem falar. A possibilidade de falar e de nomear a violência é reconhecida pelo próprio homem como o primeiro passo para uma revolta que vai além de uma reação de defesa física: é por isso que tem se medo de que as mulheres falem.

\section{CONCLUSÕES}

Hoje em dia, a situação das trabalhadoras domésticas está mudando, pelo menos nas cidades grandes. Existe a convicção de que as condições gerais do trabalho doméstico melhoraram, havendo mais informações, e a mentalidade que definia o trabaIho doméstico como submissão total é abertamente criticada?.

As mulheres pobres e as mulheres negras têm mais espaços públicos para reivindicar seus direitos como trabalhadoras. Trata-se de uma mudança que é resultado de uma transformação que diz respeito à sociedade brasileira inteira e que tem que ser reatada ao longo processo de lutas pela democratização, não somente da política, mas também da sociedade, iniciado nos anos 1970 e dentro do qual os grupos de mulheres e de mulheres negras desempenharam um papel central. Um elemento fundamental nesse processo corresponde à afirmação dos sindicatos que contribuíram para reforçar a posição das empregadas domésticas como sujeitos de direito, como cidadãs, obtendo em 2013 o reconhecimento dos mesmos direitos dos outros trabalhadores (Emenda Constitucional 72/2013) e lutando para definir o trabalho doméstico como trabalho.

7 Essas mudanças desencadearam obviamente uma resposta por parte das elites (homens e mulheres) na tentativa de recolocar a trabalhadora doméstica no lugar (inferior) dela. Vejam-se algumas considerações em Pinheiro-Machado: "A minha empregada é muito abusada”. Disponível em: <http://www.cartacapital. com.br/sociedade/201cminha-empregada-e-muito-abusada201d-7617.html . 


\section{temporalis}

As sindicalistas e as empregadas domésticas entrevistadas mencionaram alguns elementos que permitiram um melhoramento das condições de vida e de trabalho das trabalhadoras domésticas. Hoje as empregadas domésticas dão um grande valor ao direito de ter uma vida própria e o seu próprio domicílio, evitando dormir no lugar de trabalho, que se transformava frequentemente em uma prisão. O que se procura eliminar é justamente essa dimensão de intimidade que a presença constante na casa dos empregadores garantia e contribuía para apagar o caráter profissional do trabalho doméstico. As empregadas, assim como as sindicalistas, estão fazendo esforços para quebrar essa dimensão da desigualdade na intimidade. As trabalhadoras domésticas entrevistadas enfatizaram a importância dos meios de comunicação (TV, telenovelas, jornais, internet), vistos como instrumentos susceptíveis de fazer circular as notícias, de denunciar, percebidos como uma espécie de aliados. Os telefones celulares mudaram incrivelmente a condição de isolamento na qual viviam as empregadas domésticas. Além disso, eles podem igualmente ser usados para gravar filmes ou arquivos em áudio, sendo apresentados pelas sindicalistas como uma ferramenta para poder provar a violência sofrida.

É relevante nos perguntarmos o que caracteriza essa violência em comparação com as outras violências sexuais e sexistas. Existem vários pontos que fazem com que se trate de uma violência sexual e sexista, assim como ela se caracteriza fora ou dentro do lugar de trabalho: a dificuldade de provar a violência sofrida, a diferença da importância dada à palavra do homem e a da mulher, a ideia pela qual o homem tem o direito de ter relações sexuais com uma mulher, independentemente da vontade dela ${ }^{8}$. Porém, o que caracteriza esse tipo de violência é a passagem de trabaIho doméstico remunerado a um serviço sexual pedido e imposto com a força dentro de um contexto onde se concentram diferentes relações de poder típicas da sociedade brasileira: de classe, de sexo e de "raça".

8 Há também outros pontos em comum com a experiência da violência dos homens contra as mulheres, por exemplo, a ideia de que a causa da violência seria externa ao agressor (bebida, perda de controle), retirando dele a responsabilidade por seus atos. A esse respeito, ver Queiroz (2008). 
No caso dos abusos sexuais contra as empregadas domésticas, acontecem simultaneamente várias formas de opressão social, o sexismo, o classicismo e o racismo, e ao mesmo tempo uma forma específica de sexismo, de racismo e de classicismo. Nessas formas de opressão social, as variáveis sociológicas de "raça", classe e sexo se entrelaçam produzindo e reafirmando representações específicas sobre o que significa ser um homem branco de classe média e uma mulher de classe baixa, negra ou não branca, empregada doméstica. É importante lembrar que os homens que não assediaram sexualmente as empregadas domésticas perceberam essa violência como possível, como uma coisa legítima e constitutiva da formação social deles como jovens homens brancos de classe média alta. A questão do racismo, a que menos é discutida e reconhecida nos relatos, é, todavia, central pela forma específica na qual se dá no Brasil a relação entre cor/"raça" e classe, em que o conteúdo dessas categorias se define recíproca e contemporaneamente (SILVA, 1999; MCCALLUM, 2005).

Outra característica, em comparação com as outras violências sexuais, reside no fato de que esses abusos acontecem em casa, ao mesmo tempo local de trabalho remunerado e espaço da intimidade familiar, criando uma confusão entre o que faz parte do trabalho e o que está ligado a relações afetivas e de cuidado. Todas as sindicalistas sublinharam como a dimensão do isolamento, da solidão na qual vivem as empregadas domésticas, sobretudo no passado, produz não somente uma exposição maior a um risco de violência, mas também a extrema dificuldade de se perceberem como sujeitos de direitos e que pertencem a uma categoria profissional. O isolamento pode gerar uma falta de percepção da sua própria posição social como trabalhadora. $\mathrm{Na}$ opinião de uma sindicalista, com o fato de não morar no local de trabalho e usar os meios de transportes públicos, "você tem convivência com os outros trabalhadores, você troca". Morar na casa onde se trabalha tem por efeito sentir-se desapropriada de si e, em alguns casos, de não mais se ver como uma trabalhadora. Não morar na casa onde trabalham ajudaria as empregadas a contornar os episódios de abusos sexuais, não tanto porque elas arriscariam menos de se encontrar sozinhas com um homem da 


\section{temporalis}

casa, mas porque construiriam uma percepção de si como subjetividade independente, tendo direitos a serem respeitados.

O quadro que aparece dos relatos dos homens e das empregadas domésticas permite compreender como se combinam nas violências contra as trabalhadoras domésticas várias formas de opressão social, não somente aquela baseada no sexo, mas também na classe e na "raça". Todavia, enquanto nas entrevistas com os homens o discurso sobre as opressões de classe e sexual é presente e articulado, mesmo segundo modalidades diferentes, o discurso sobre a opressão racista quase sempre fica inarticulado ou articulado por dentro da dimensão histórica da escravidão, distanciando assim o problema no passado. A dimensão do racismo presente nos abusos sexuais contra as empregadas domésticas tende a ser apagada ou considerada irrelevante, também porque a própria cor branca não é tratada pelos entrevistados como elemento relevante para compreender as relações com as trabalhadoras domésticas. O dado mais interessante, talvez, é que os homens, mesmo não considerando a própria cor e a da trabalhadora doméstica como elemento importante na questão dos abusos sexuais, fornecem nos próprios relatos um material rico para entendermos o quanto o racismo estrutura essa relação de trabalho e os abusos sexuais que nela podem ocorrer.

A comparação entre os relatos dos homens e os das empregadas domésticas e das sindicalistas sobre os abusos sexuais ofereceu a possibilidade de entender não apenas a experiência da dominação, mas também a conflitualidade e as resistências a esta. A análise do discurso dos homens permitiu compreender como a violência contra as empregadas domésticas está susceptível de ser naturalizada e, então, aceita por eles como inevitável. Segundo Acker (2000), os grupos domintantes, ao definirem como inevitáveis as relações de poder das quais participam, as legitimam. Ao contrário, o discurso das empregadas domésticas e das sindicalistas está orientado na direção de uma perspectiva de mudança, de luta, vivida pelas subjetividades individualmente ou através das experiências coletivas sindicais. Como diz uma empregada doméstica de 70 anos, aposentada: “Agora eu me defendo. Agora sei me defender. Mas na época ainda não era igual agora. 
Agora as coisas tá muito esclarecida. A imprensa fica em cima, você fica fazendo trabalho [...]".

\section{REFERÊNCIAS}

ACKER, J. Revisiting Class: thinking from Gender, Race, and Organizations. Social Politics, v. 7, n. 2, p. 192-214, 2000.

ÁVILA, M. B. Algumas questões teóricas e políticas sobre emprego doméstico. In: ÁVILA, M. B. et al. (Org.). Reflexões feministas sobre informalidade e trabalho doméstico. Recife: SOS CORPO, 2008. p. 65-72.

ÁVILA, M. B. Divisão sexual do trabalho e emprego doméstico no Brasil. In: COSTA, A. et al. (Org.). Divisão sexual do trabalho, estado e crise do capitalismo. Recife: SOS Corpo, 2010. p. 115-144.

BERNARDINO-COSTA, J.; FIGUEIREDO, Â.; CRUZ, T. (Org.). A realidade do trabalho doméstico na atualidade. Brasília: Centro Feminista de Estudos e Assessoria, 2011.

BRITES, J. Afeto e desigualdade: gênero, geração e classe entre empregadas domésticas e seus empregadores. Cadernos Pagu, n. 29, p. 91-109, 2007.

CRENSHAW, K. Demarginalizing the Intersection of Race and Sex: a Black Feminist Critique of Antidiscrimination Doctrine, Feminist Theory and Antiracist Politics. University of Chicago Legal Forum, n. 139, p. 139-67, 1989.

- Mapping the Margins: Intersectionality, Identity Politics \& Violence Against Women of Color. Stanford Law Review, n. 43, p. 1241-99, 1991.

FIGUEIREDO, A. Novas elites de cor: estudo sobre os profissionais negros de Salvador. São Paulo: AnnaBlume, 2002.

GOLDESTEIN, D. Laughter out of Place: Race, Class, Violence, and Sexuality in a Rio Shantytown. Berkeley; Los Angeles: University of California Press, 2003. 


\section{tempordils}

INSTITUTO DE PESQUISA ECONÔMICA APLICADA - IPEA. Situação atual das trabalhadoras domésticas no país. Comunicados do Ipea, n. 90, Rio de Janeiro: IPEA, 2011.

KERGOAT, D. Dynamique et consubstancialité des rapports sociaux. In: DORLIN, E. (Org.). Sexe, Race, Classe, pour une épistémologie de la domination, Actuel Marx Confrontation. Paris: PUF, 2009. p. 111-126.

KOFES, M. S. Entre nós mulheres, elas as patroas, elas as empregadas. In: ARANTES, A. et al. (Org.). Colcha de retalhos: estudos sobre a família no Brasil. Campinas: Editora da Unicamp, 1993. p. 185-194.

KOFES, M. S. Mulher, Mulheres: identidade, diferença e desigualdade na relação entre patroas e empregadas. Campinas: Editora da Unicamp, 2001.

MATA, da Azeredo S. M. Relações entre empregadas e patroas: reflexões sobre o feminismo em países multirraciais. In: COSTA, A.; BRUSCHINI, C. (Org.). Rebeldia e submissão: estudos sobre a condição feminina. São Paulo: Fundação Carlos Chagas, 1989. p. 195-220.

MATHIEU, N.-C. Quand céder n'est consentir. In: L'anatomie politique. Paris: Côté-femmes, 1991. p. 131- 225.

MELO, H. Pereira. Feminists and Domestic Workers in Rio de Janeiro. In: CHANEY, E.; CASTRO GARCIA, M. (Org.). Muchachas no more: household Workers in Latin America and the Carebbean. Philadelphia: Temple University Press, p. 245-267.1989.

MELO, H. Serviço doméstico remunerado no Brasil: de criadas a trabahadoras. Texto para discussão n. 565. Rio de Janeiro: IPEA, 1998.

McCALLUM, C. Racialized Bodies, Naturalized Classes: moving through the City of Salvador da Bahia. American Ethnologist, v. 32, n. 1, p. 100-117, 2005. 
MCCALLUM, C. Women out of Place? A Micro-historical Perspective on the Black Feminist Movement in Salvador da Bahia, Brazil. Journal of Latin American Studies, v. 39, n. 1, p. 55-80, 2007.

OLIVEIRA, A. M.; CONCEIÇÃO, O. M. Domestic Workers in Rio de Janeiro: Their Struggle to Organize. In: CHANEY, E.; CASTRO GARCIA, M. (Org.). Muchachas no more: household Workers in Latin America and the Carebbean. Philadelphia: Temple University Press, 1989. p. 363-372.

OLIVEIRA, C. M. A organização política das trabalhadoras domésticas no Brasil. In: ÁVILA, M. B. et al. (Org.). Reflexões feministas sobre informalidade e trabalho doméstico. Recife: SOS CORPO, 2008. p. 109-116.

OWENSBY, Brian P. Intimate Ironies: modernity and the Making of Middle Class Lives in Brazil. Standford: Standford University Press, 1999.

PINHO, P. de Santana; SILVA, E. B. Domestic Relations in Brazil: legacies and Horizons. Latin American Research Review, v. 45, n. 2, p. 90-113, 2010.

QUEIROZ, F. Marquez. Não se rima amor e dor: cenas cotidianas de violência contra a mulher. Mossoró: Editora da UERN, 2008.

RIBEIRO COROSSACZ, V. L'apprendimento della mascolinità tra uomini bianchi di classe medio-alta a Rio de Janeiro. In: RIBEIRO COROSSACZ, V.; GRIBALDO, A. (Org.). La produzione del genere: ricerche etnografiche sul femminile e sul maschile. Verona: Ombrecorte, 2010. p. 113-133.

. Entre cor e classe. Definições de branquitude entre homens brancos do Rio de Janeiro. Revista da ABPN (Associação Brasileira de Pesquisadores Negros) - Dossiê Branquitude, v. 6, n. 13, p. 201-222, mar./jun., 2014a. Disponível em: <http://www. abpn.org.br/Revista/index.php/edicoes/issue/view/16/showToc>. Acesso em: 3 out. 2014 . 


\section{temporalis}

. Cor, classe, gênero: aprendizado sexual e relações de domínio. Estudos Feministas, v. 22, n. 2, p. 521-542, 2014b.

- Whiteness, Maleness and Power: a study in Rio de Janeiro. Latin American \& Caribbean Ethnic Studies, v. 10, n. 2, 2015, no prelo.

SANTOS, R. J. Corpos domesticados: a violência de gênero no cotidiano das domésticas em Montes Claros - 1959 a 1983. 2009. Dissertação (Mestrado em História Social) - Programa de Pós-Graduação em História Social, Universidade Federal de Uberlândia, Uberlândia, 2009.

SANTOS-STUBBE, C. Cor, cultura e sociedade: a questão da etnicidade entre as empregadas domésticas. Estudos afro-asiáticos, n. 33, p. 51-69, 1998.

SILVA, N. V. Uma nota sobre raça social no Brasil. In: HASENBALG, C.; SILVA, N. V.; LIMA, M. Cor e estratificação social. Rio de Janeiro: Contracapa, 1999. p. 107-125.

SILVA, E. Maids, Machines and Morality in Brazilian homes. Feminist Review, v. 94, n. 1, p. 20-37, 2010.

SILVA, G. M.; REIS, E. Perceptions of Racial Discrimination among Black Professionals in Rio de Janeiro. Latin American Research Review, v. 46, n. 2, p. 55-78, 2011.

WADE, P. Articulation of erotization and race: domestic Service in Latin America. Feminist Theory, v. 14, n. 2, p. 187-202, 2013. 